\title{
The Firing of Hippocampal Place Cells in the Dark Depends on the Rat's Recent Experience
}

\author{
Gregory J. Quirk,' Robert U. Muller, ${ }^{1}$ and John L. Kubie ${ }^{2}$ \\ 'Departments of Physiology and ${ }^{2}$ Anatomy and Cell Biology, State University of New York at Brooklyn, \\ Brooklyn, New York 11203
}

\begin{abstract}
Hippocampal "place cells" fire when a freely moving rat is in a given location. The firing of these cells is controlled by visual and nonvisual environmental cues. The effects of darkness on the firing of place cells was studied using the task of Muller et al. (1987), in which rats were trained to chase randomly scattered food pellets in a cylindrical drum with a white cue-card attached to the wall. The position of the rats was tracked via an infrared LED on the headstage with a video system linked to computer. Two experimental protocols were used: in the first, lights were turned off after the rat had already been placed in the chamber; in the second, the rat was placed in the darkened chamber. The dark segments produced by these 2 methods were identical with respect to light and other cues but differed with respect to the rat's experience. The firing patterns of 24 of 28 cells were unaffected by darkness when it was preceded by a light period. In contrast, the firing patterns of 14 of 22 cells changed dramatically when the rats were put into the darkened chamber. Furthermore, the majority of cells that changed their firing pattern in initial darkness maintained that change when the lights were turned on. These results show that place cells can fire differently in identical cue sltuations and that the best predictor of firing pattern is a combination of current cues and the rat's recent experience. The results are discussed in terms of mnemonic properties of hippocampal cells and "remapping" of place cell representations.
\end{abstract}

The context of this paper is the spatial theory of hippocampal function proposed by O'Keefe and Nadel (1978). In this theory, the rat hippocampus is taken to be an essential part of a maplike representation of the environment that is used by the rat to solve complex spatial problems. As originally stated, the theory assumed that the map-like representation is entirely confined to the hippocampus and that the representation is the sole function of the hippocampus. There are now several lines of evidence that other brain regions are part of the representation (Kolb et al., 1982; Quirk et al., 1989; Taube et al., 1990a, b). In addition, it is by no means clear that the function of the hippocampus is confined entirely to the spatial sphere (Olton et al., 1979; Berger et al., 1983; Wiener et al., 1989). Never-

\footnotetext{
Received Aug. 30, 1989; revised Dec. 27, 1989; accepted Jan. 30, 1990.

This work was supported by research grants NS 20686, NS 14497, and NS 07114. We wish to thank Dr. James B. Ranck, Jr., for useful discussions and comments on the manuscript. We also thank Dr. Daniel Tranchina for help in making the light-level measurements.

Correspondence should be addressed to Gregory J. Quirk, Department of Physiology, Box 31, State University of New York at Brooklyn, Brooklyn, NY 11203. Copyright (c) 1990 Society for Neuroscience 0270-6474/90/062008-10\$02.00/0
}

theless, it seems equally clear that a fully correct theory will have to include the central notion that the rat hippocampus is profoundly involved with mapping the environment and guiding spatial behavior.

The spatial theory rests on 2 main lines of evidence. In the first place, hippocampal lesions interfere with the ability of rats to learn and often to perform complex spatial tasks (Olton et al., 1978; Morris ct al., 1982; Jarrard, 1983). Aspects of spatial problem solving are impaired after other lesions (Sutherland et al., 1983), but there is no doubt that an intact hippocampus is required for the rat to have normal spatial abilities.

The second line of support for the spatial theory is the "place cell" phenomenon discovered by O'Keefe and Dostrovsky (1971). Place cells are named for the fact that their firing is locationspecific; they fire rapidly only when the rat is in a particular part of its surroundings and are virtually silent outside the region of intense activity (the "firing field"). Place cell firing has been recorded under conditions in which the rat's behavior is nearly homogeneous in time and space, suggesting that location specificity does not arise merely because the rat performs firingrelated behaviors only within the firing field (Muller et al., 1987).

O'Keefe and Conway (1978) demonstrated that experimenterdefined cues within an isolated region are able to control the firing of hippocampal place cells by rotating the cues relative to the laboratory frame. They found that the cue rotations caused equal rotations of spatial firing patterns. Muller and Kubie (1987) showed that it is possible to find conditions in which cue control is exerted by a single visual cue, namely, a white card attached to the wall of a gray cylinder, again by showing that rotations of the card produce equal rotations of place cell firing fields.

The special importance of visual input under the circumstances used by Muller and Kubie (1987) raises the question of what would happen to place cell firing if all visual cues were removed by darkening the recording apparatus. Several lines of evidence from previous work in lighted recording chambers suggest that the firing of place cells in the dark would be similar to that seen in the light. Muller and Kubie (1987) reported that removing the cue card from he recording chamber had little effect on firing patterns. Card removal often induced rotations of fields to unpredictable positions, but left the size, shape, and radial position of fields unchanged. O'Keefe and Conway (1978) showed that firing patterns were constant when 1 or 2 of a set of 4 cues was deleted. Thus, stimulus control over place cell firing may be exerted by multiple, discrete objects. In addition, because O'Keefe and Conway (1978) used stimuli of different sensory modalities, they were able to conclude that control over location-specific firing was polymodal; auditory, olfactory, and tactile stimuli were effective in addition to visual stimuli. O'Keefe 
and Speakman (1987) obscrved persistence of firing fields following removal of all of the controlling cues, but only if the cues were removed in the presence of the rat, thus demonstrating that the current state of the place cell system can be influenced by a previous state (a form of memory).

In addition to indirect evidence, O'Keefe (1976) and Hill and Best (1981) reported that firing fields persist in darkness. O'Keefe (1976), however, tracked rals either by watching them in the presence of dim red light or by holding the tail as the rat moved around; either method could supply the essential information for reliable location-specific firing. In addition, neither of the earlier studies used quantitative methods for assessing the degree to which firing fields remained stable in the dark. The first purpose of the present study is therefore to investigate the claim of persistence of spatial firing in the dark in circumstances where visual stimuli are known to be important, using automatic video tracking of an infrared source on the rat's headstage. Spatial firing patterns in the dark will be measured and compared to firing patterns in the light to quantify the amount of persistence. Variations in the amount of persistence in the dark may indicate that different cells receive different combinations of polymodal sensory input.

The second major purpose of this paper is to assess the influence of previous states of the environment on place cell firing in the dark. To accomplish this, a method reported in a brief communication on the firing of dentate granule cells will be used (Jones-Leonard et al., 1985). The effects of darkness on place cell firing in the cylinder will be examined under 2 conditions. In the first, the lights will be turned off with the rat already in the recording chamber; whereas in the second, the rat will be placed into the recording chamber when it is already dark. In both dark conditions, the available sensory information is the same, but the recent experience of the rat is different. The firing of individual cells in the 2 dark segments will be compared to see if the state of the environment at the beginning of the dark period influences the firing patterns. In addition, after measurements in initial darkness, the lights will be turned on to test the effects of adding visual cues. These manipulations allow us to test the extent to which place cell firing can be dissociated from the immediately available cue configuration and can supply additional information about the role of recent memory in establishing the current hippocampal representation of the environment. Some of these results have appeared in preliminary form (Quirk et al., 1987).

\section{Materials and Methods}

Behavioral training. Two recording chambers were used. One was a cylinder $76 \mathrm{~cm}$ in diameter and the other was a square $69 \mathrm{~cm}$ on a side. Both chambers were $51 \mathrm{~cm}$ high and gray in color. The gray floor paper was replaced after each recording session. The recording chamber was placed on the floor and was surrounded by a brown circular curtain, $1.5 \mathrm{~m}$ in diameter and $2 \mathrm{~m}$ high. A white cue card covered $100^{\circ}$ of arc in the cylinder, and an entire wall in the square. Earlier work (Muller and Kubie, 1987) showed that the card exerted almost ideal stimulus control over the angular position of firing fields in this visually simplified environment. The card was always located at 3 o'clock in the cylinder and on the right-hand wall in the square; at no time was the card removed from either chamber. Lighting in the recording room was provided by four $15 \mathrm{~W}$ lamps symmetrically oriented on the ceiling.

During training, rats were food-deprived and placed into the cylinder to chase after $20 \mathrm{mg}$ food pellets tossed in by the experimenter. Daily training sessions lasted about $15 \mathrm{~min}$, during which pellets were tossed in at a rate of $3-4 / \mathrm{min}$. Since the pellets scattered widely, the rat ran over the entire floor while retrieving them. After approximately $10 \mathrm{~d}$, the rats spent almost all of their time moving in the chamber. Following training in the cylinder, the rats received similar training in the square chamber, where they quickly adapted. Ten rats were trained this way.

In addition to training in the light, 8 rats also learned to retrieve pellets in the dark. The rat was placed into the lighted chamber. After several minutes, the lights were turned off for $5 \mathrm{~min}$ and were then turned back on. Each rat experienced two 5 min dark intervals in both the cylinder and square.

At the end of training, the rats had received approximately 15 exposures to the testing chamber over a period of 2 weeks. The rats were intentionally overtrained in this simple task so that cells could be recorded in the behavioral steady state, following a presumed initial learning period. We emphasize that by the time the first place cell was isolated, each rat was thoroughly familiar with the environments.

To verify that the darkness in the recording room was nearly total, light levels were measured with an optometer (model 161, United Detector Technologies, Hawthorne, CA). With the room lights on, the light level was $164.0 \mu \mathrm{W} / \mathrm{cm}^{2}$. The lights were then turned off and the aperture of the optometer was covered with a plastic cap. The reading under these circumstances was $0 \mu \mathrm{W} / \mathrm{cm}^{2}$. When the cap was removed, the optometer measured at most $1.0 \times 10^{-4} \mu \mathrm{W} / \mathrm{cm}^{2}$, which is 37 times below the behaviorally defined threshold for vision in dark-adapted hooded rats (Muntz, 1967).

Electrode implantation. Following training, the rats were implanted with a microdrive which contained a movable bundle of ten $25 \mu$ wires (Kubie, 1984). Surgery was performed under Nembutal anesthetic (50 $\mathrm{mg} / \mathrm{kg}$ ). The electrode array was aimed just above the dorsal hippocampus, with coordinates of $4.0 \mathrm{~mm}$ posterior to bregma, $3.5 \mathrm{~mm}$ lateral to the midline (right side), and $1.7 \mathrm{~mm}$ ventral to the brain surface, with the skull flat (Paxinos and Watson, 1982). The electrode was tilted $8^{\circ}$ in the coronal plane to allow a normal intersection with the CAl pyramidal cell layer.

The rats were killed by an overdose of Nembutal at the end of a single pass of the electrode, below the CA3 cell layer. To locate the final position of the electrode array, current was passed through one of the wires to produce an iron deposit at the electrode tip that was visualized with the Prussian blue reaction. The positions of cells encountered throughout the pass were calculated back from the blue spot.

Recording. Testing for unit activity began $5 \mathrm{~d}$ after surgery. Screening for units was done in either the cylinder or square. The screening apparatus for each rat was randomly selected each time the animal was tested. If no units could be discriminated, the microdrive was advanced $50 \mu \mathrm{m}$. This sequence was repeated twice per day until at least one place cell could be discriminated. Only cells showing a robust firing field were used for the study. The signal from the electrode was passed through an FET source-follower mounted on the headstage and was amplified 1000 times with a Grass preamplifier set at $300 \mathrm{IIz}-10 \mathrm{kIIz}$ bandpass, $6 \mathrm{~dB} /$ octave. Three window discriminators (Bak time-amplitude, model DIS-1) connected in series were used to select the desired waveform. Acceptance pulses from the last discriminator were counted as action potentials.

The position of an infrared LED (OP160W, TRW Optoelectronics) attached to the recording headstage was monitored with a solid-state video camera. The sensitivity of the rat visual system falls off sharply at $620 \mathrm{~nm}$, well below the infrared range (Birch and Jacobs, 1975). The scanning region of the camera was divided into $64 \times 64$ square pixels measuring $2.9 \mathrm{~cm}$ on a side. A microcomputer (Hewlett Packard, model HP 86) sampled the $X$ and $Y$ coordinates of the rat's position and the spike count at $60 \mathrm{~Hz}$.

At the conclusion of the recording session, the spike and location data were written onto disk and analyzed on a Masscomp 5500 computer. Two $64 \times 64$ arrays were generated from the data. Each element in the first array (spike array) accumulated the total number of spikes that occurred in each pixel for the entire session. Each element in the second array (time-in-location array) contained the total time the rat spent in each pixel. The spike array was divided by the time-in-location array to give a rate array. The rate array can be visualized as a "rate map," which is an overhead view of the recording chamber with the area of each pixel color-coded for time-averaged firing rate. Yellow pixels encode a firing rate of exactly zero. Pixels with greater-than-zero firing rate are sorted into ascending order and divided into 5 color-coded firing rate categories. From the lowest firing rate category to the highest, the colors used are orange, red, green, blue, and purple.

Protocol. Recordings were made during 2 types of light-dark sequences. The first was $24 \mathrm{~min}$ in duration where the room lights were on for the first $8 \mathrm{~min}$, off for the middle $8 \mathrm{~min}$, and on again for the 
last $8 \mathrm{~min}$ to give a light-dark-light sequence (L-D-L sequence). The second sequence (D-L sequence) was $16 \mathrm{~min}$ in duration where the lights were off for the first $8 \mathrm{~min}$ and on for the last $8 \mathrm{~min}$, resulting in scquential dark-light scgments. Taken together, the 2 sequences yielded five 8 -min segments and separate rate maps were generated for each segment. When possible, both sequences were done in the cylinder and square for each cell. The order was as follows: The L-D-L sequence was performed in whichever chamber the place cell was discovered, followed by the L-D-L sequence in the other chamber, followed by the D-L sequence in each of the 2 chambers. The order of recording chambers for these last 2 sessions was chosen randomly so that the rat could not predict, on any given trial, into which apparatus it was being placed. Between sequences, the rat was returned to its home cage. The average time between sequences was about $30 \mathrm{~min}$. The full protocol consisted of 4 sequences: the L-D-L and D-L sequences for both the cylinder and the square. For 5 cells, a third lighted 8 -min segment was added to the above protocol.

Although every cffort was made to isolate individual action potentials for testing, we cannot rule out the possibility that what was identified as a single cell through the course of the experiment was actually 2 different cells. As will be shown, the firing patterns of cells underwent dramatic changes when the rat was placed into the dark chamber, and whether it was a single cell that changed or 2 cells, both of which changed, does not the alter the main point, namely, that significant changes in firing pattern were observed in this condition.

Data analysis. Variations in spatial firing pattern were assessed by comparing the rate arrays with a spatial firing rate cross-correlation (Muller and Kubie, 1987). To compare the firing patterns in 2 arrays, the firing rate of each pixel in one rate array is correlated with the firing rate of the corresponding pixel in a second rate array. The $Z$ transform of the resulting correlation is an estimate of the similarity of the 2 firing patterns and will hereafter be referred to as the "persistence score." If the correlation was positive and significant at the 0.001 level (singletailed $t$-test), firing in the 2 segments was classified as persistent. The 0.001 level corresponded to a correlation value of 0.137 and was used as a cut-off because it most closely agreed with judgments made by eye. In general, there was excellent correspondence between the correlation method and judgments made by eye; the 2 disagreed in only 8 out of 50 comparisons. As might be expected, the correlation values for these 8 cases fell close to the cut-off for significance. Final decisions about persistence were made on the basis of the correlation value alone.

Changes in firing rate, independent of firing pattern, were investigated by comparing the mean pixel firing rate across segments. To compute the mean pixel rate, pixels were first collapsed 3 to 2 , and the average firing rate for all pixels in the map was computed. The advantage of this measure is that it is not influenced by how much time the rat spends in or out of the firing field.

In the figures of rate maps, the color code for the firing rate for a given cell is the same for all segments of the protocol for that cell and is set according to the firing rates observed in the initial lighted segment. This facilitates comparison of rate maps in different segments for changes in firing rate.

\section{Results}

Twenty-eight complex-spike cells recorded from the dorsal hippocampus of 10 rats were studied. Histological analysis showed that 7 cells were in CA1 and 19 in CA3/4. Histological data were unavailable for one rat from which 2 cells were obtained. Since no differences were observed between CA1 and CA3/4 cells, they were combined into a single group. The average duration of the negative-going portion of the waveform was 0.31 $\pm 0.07 \mathrm{msec}$, in the range expected for complex-spike cells (Ranck, 1973).

Cells were chosen for the study if they exhibited a strong firing field only in the cylinder (16 units), only in the square (5 units) or in both ( 7 units). For cells with fields in both chambers, the effects of darkness are reported for the chamber that was judged by the experimenters to be associated with the more robust firing field. Of the 7 such cells, the analysis was made in the cylinder for 6 and in the square for 1 . Thus, the effects of darkness are given for 22 cells in the cylinder, and for 6 cells in the square.

\section{Effects of darkness immediately preceded by light}

We begin by describing the effects of turning off the room lights after the rat had been put into the recording chamber in the light. Figure 1 shows rate maps for the three 8-min segments for the L-D-L sequence from 4 cells. In each row, firing rate categories were selected from the rate distribution in the first lighted segment according to an autoscaling procedure (see Materials and Methods). The same categories were then used to color-code each map for a given cell. All rate maps in this paper are color-coded in this way.

As exemplified by the cells in rows A and B of Figure 1, the firing patterns of most units persisted in the dark. By inspection, the firing patterns of these 2 cells in the dark segment (Fig. 1, $A 2, B 2$ ) were virtually the same as the patterns in either the preceding or following lighted segment. The patterns are similar in terms of position, firing field area, and shape. In addition, the in-field firing rate is nearly constant. This is seen from invariant numbers of pixels coded in a given color across segments. As expected from the similar spatial firing patterns, the persistence score (cross-correlation between the first light and dark segments) was 0.57 for the first cell and 0.58 for the second. These are rather high scores for the cell sample, as seen in the persistence histogram in the upper part of Figure 2.

The weaker persistence $(0.34)$ of the place cell in row $C$ was near the mean of the sample (0.38). In this case, it is clear that the firing rate of the cell underwent a large decrease in the dark (Fig. 1C2). It is also clear that the remaining firing occurred in the expected place, accounting for the moderate persistence score. In the last example of Figure 1, the robust firing field seen in the light (Fig. 1DI) disappears when the lights are turned off. The peak rate and overall rate decrease, and the firing is scattered. The persistence score of 0.13 is near the low end of the distribution shown in the top of Figure 2. This is just below the value of 0.14 (marked with an arrowhead in Fig. 2) that we selected as a cut-off to separate persistent from nonpersistent cells. This value corresponds to the 0.001 level of probability for the pixel-by-pixel correlation between 2 spatial firing distributions with about 500 pixels in each. The separation made in this way found that there were 24 persistent and 4 nonpersistent cells and was in excellent agreement with judgments about the entire sample made by visual inspection.

By visual inspection, the spatial firing patterns of most cells were also similar during the initial and final lighted segments of the L-D-L sequence. The firing patterns in the 2 lighted segments are nearly the same for the cells in rows $A$ (persistence $=0.68$ ) and $\mathrm{B}$ (persistence $=0.56$ ) of Figure 1 , as can be seen by comparing columns 1 and 3 . The same comparison for cell $\mathrm{C}$ (persistence $=0.62$ ) shows that its firing rate partially recovered from the low rate seen during darkness. For cell D, it is seen that the spatial firing pattern approximated its initial form when the lights were turned back on, although the persistence of 0.20 was fairly low.

The numerical method classified 22 of 24 cells as persistent in the 2 lighted segments; the distribution of persistences is shown in the histogram of Figure $2 B$. The mean L-L persistence was 0.39 , and was virtually identical to the mean L-D persistence of $0.38[t=0.14 ; d f=53 ; p(t>0.14)=0.45]$. Note that the persistence between 2 lighted segments is effectively a measure of the firing pattern reproducibility for a pair of $8 \mathrm{~min}$ recording sessions under identical conditions. The near equality of the L-L and L-D mean persistence reinforces the idea that darkness had little effect on firing. 


\section{LIGHT-DARK - LIGHT}

A 1

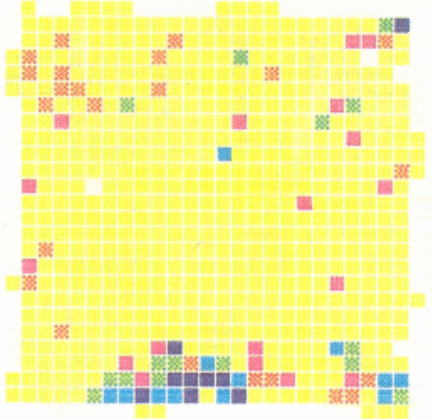

B

1

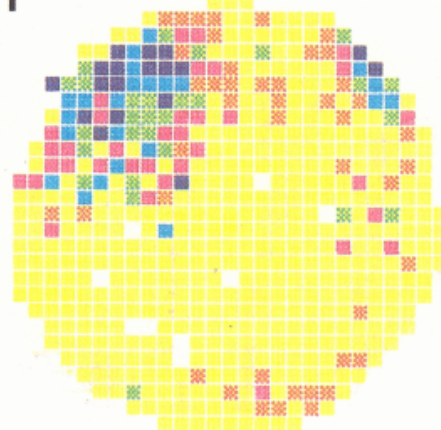

1

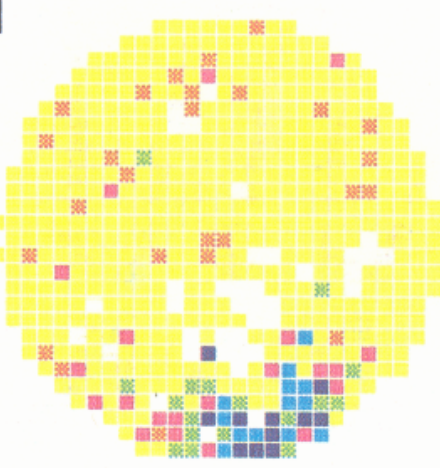

1

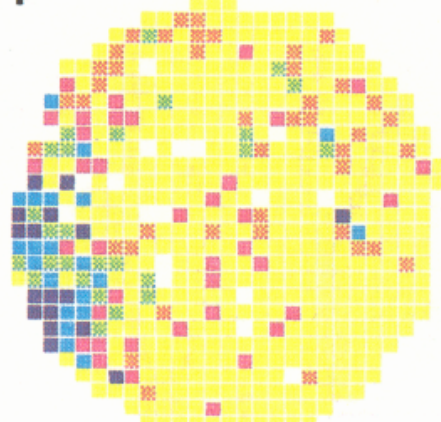

2

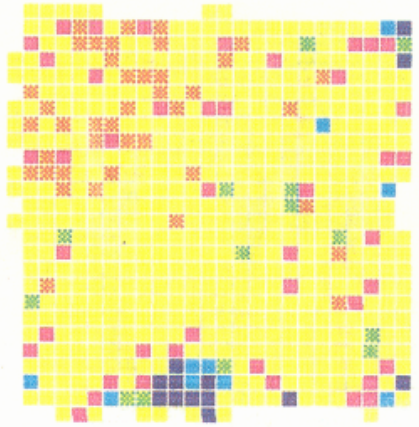

2

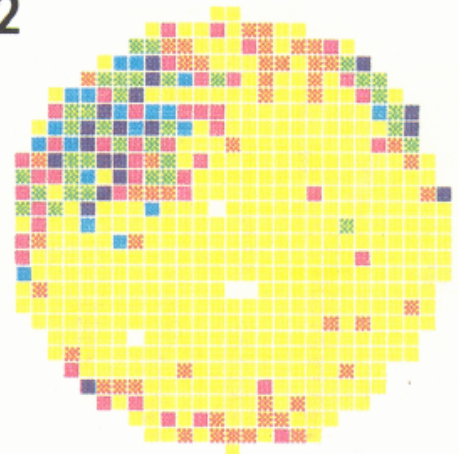

2

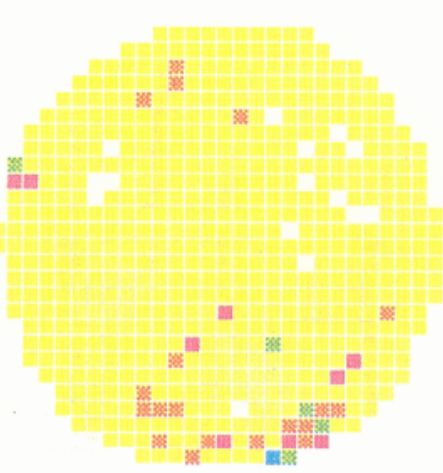

2

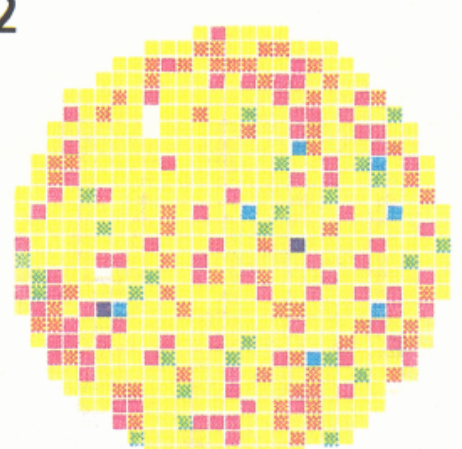

3

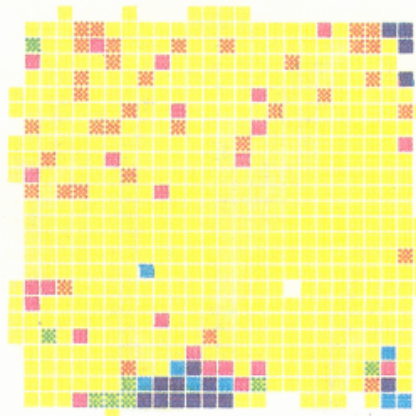

3

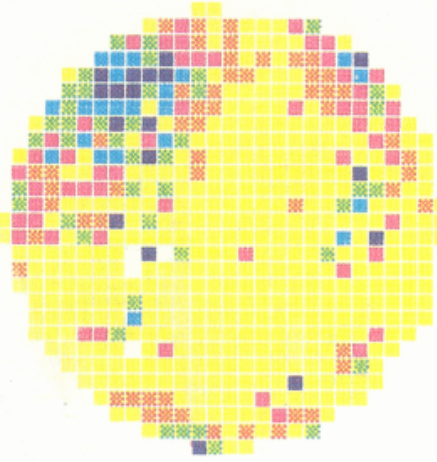

3

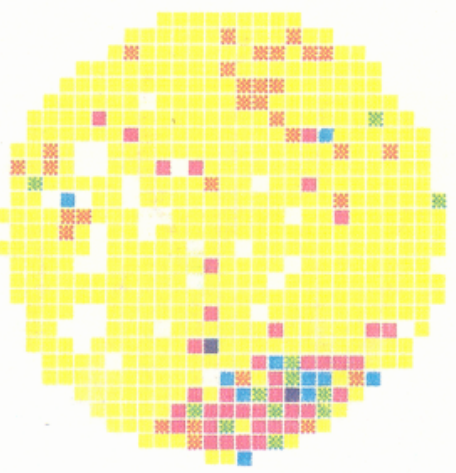

3

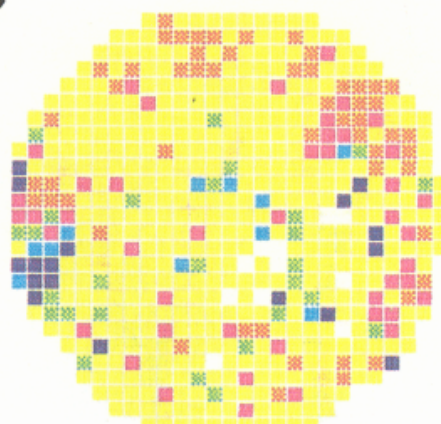

Figure 1. Four hippocampal place cells tested in the light-dark-light sequence. The 3 firing rate maps in each row correspond to the 3 segments of the L-D-L sequence. Cells A and B show strong persistence of spatial firing in the dark in the square and cylinder chambers, respectively. Cell $\mathrm{C}$ weakly persisted, and cell $\mathrm{D}$ failed to persist. The persistence scores between the maps are as follows: cell $A, \mathrm{~A} 1: \mathrm{A} 2=0.57, \mathrm{~A} 1: \mathrm{A} 3=0.68, \mathrm{~A} 2$ : $\mathrm{A} 3=0.83 ;$ cell $B, \mathrm{~B} 1: \mathrm{B} 2=0.58, \mathrm{~B} 1: \mathrm{B} 3=0.63, \mathrm{~B} 2: \mathrm{B} 3=0.46 ;$ cell $C, \mathrm{C} 1: \mathrm{C} 2=0.34, \mathrm{C} 1: \mathrm{C} 3=0.62, \mathrm{C} 2: \mathrm{C} 3=0.21 ;$ cell $D, \mathrm{D} 1: \mathrm{D} 2=0.13, \mathrm{D} 1: \mathrm{D} 3$ $=0.20, \mathrm{D} 2: \mathrm{D} 3=0.08$. Median firing rates of pixels are as follows (order: yellow, orange, red, green, blue, purple, in Hz.): cell $A, 0.0,0.69,1.71$, $3.00,6.49,10.00$; cell $B, 0.0 .0 .83,2.86,5.33,9.14,14.60$; cell $C, 0.0,0.61,2.50,6.00,11.61,20.00 ;$ cell $D, 0.0,0.92,2.22,4.38,7.32,11.35$. 

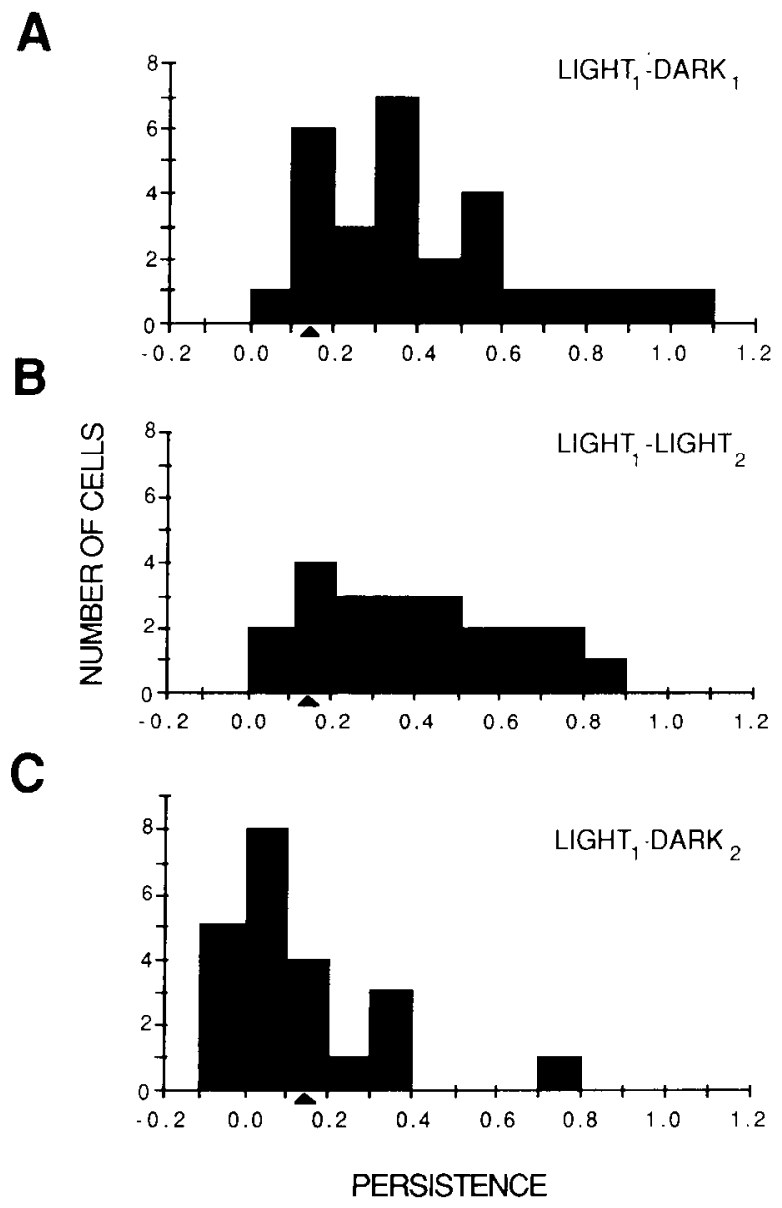

Figure 2. Histograms showing the distributions of the persistence scores between the initial lighted segment and $(A)$ the dark segment of the L-D-L sequence, $(B)$ the light segment of the L-D-L sequence, and $(C)$ the dark segment of the D-L sequence. The triangle at 0.14 on the abscissa marks the cut-off for significance at the 0.001 level.

In addition to calculating persistence, we also estimated the overall firing rate for each cell in the 3 segments as the mean rate in small rectangular regions. To increase the accuracy of the estimates, the dwell time and total number of spikes from 4 adjacent pixels were summed to form the rectangular regions. Averaged over cells, the mean firing rates were were 1.01, 1.04, and 1.29 for the 3 segments of the L-D-L sequence. The mean ratio of the rate in the first segment to the rate in either the second or third segments was not statistically different from 1 . About half the cells (16/28) showed a rate decrease in the dark; the remainder showed a rate increase (see Figs. 1, 3, and 5, columns 1 and 2).

\section{Effect of initial darkness on the firing of place cells}

It is possible that information registered in the first lighted segment of the L-D-L sequence was important for the persistent spatial firing in the dark. We therefore compared the firing patterns from the dark segment of the L-D-L sequence with those obtained by placing the rat directly into the darkened chamber. After $8 \mathrm{~min}$ in the dark, the lights were turned on and recording was continued for an additional $8 \mathrm{~min}$ (D-L sequence). Of the 28 cells, 22 were tested this way.

In contrast to the modest changes in spatial firing caused by turning off the lights while the rats were in the apparatus, spatial firing patterns of more than half the place cells were strongly altered when the rat was put into the apparatus in the dark. Figure 3 shows 3 examples of cells that persisted throughout the L-D-L sequence but changed firing patterns in initial darkness. In all 3 cases, the firing pattern in the initial dark segment (maps A4, B4, and $\mathrm{C} 4$ ) bear little resemblance to the original lighted patterns. The persistence measure indicated that 14 of 22 cells showed a new firing pattern when firing patterns in the light were compared to firing patterns in initial darkness. Figure $2 C$ is a histogram of the persistence between initial light and initial dark segments. The proportion of persistent cells in initial darkness was significantly lower than the proportion of persistent cells seen in the L-D-L sequence, according to a Fisher exact probability test $(p<0.001)$. The mean persistence score in initial darkness was $0.137(n=22)$, significantly lower than that observed in the L-D-L sequence $[d f=48, t=4.0, p(t>$ $4.0)<0.001]$. The mean pixel firing rate of cells in initial darkness $(1.23 \mathrm{~Hz})$ was not statistically different from firing in the light. In contrast, firing rates in initial darkness were more variable than in darkness preceded by light $\left[F_{20.28}=4.15, p(F>\right.$ $4.15<0.001]$.

Closer inspection of the 14 cells that changed in initial darkness revealed 3 types of changes in firing pattern. In the first place, 6 of the 14 cells showed firing fields in different locations from those in the light. These new firing fields had no discernible relationship to ficlds seen in initial light, differing in location, size, and shape. For example, cell A in Figure 3 fired mostly in the upper left-hand corner in the L-D-L sequence but displayed a center-field in initial darkness. Note that the firing rate of the new field (map A4) was equal to that in the preceding segment (map A3). Second, 3 of the 14 altered cells had fields that were degraded versions of the firing field seen in the light; an example is shown in Figure 3, map B4. The firing rate of this cell was reduced in initial darkness. Finally, 5 cells were virtually silent in initial darkness even though they had clear firing fields in initial light; cell $C$ in Figure 3 is an example of this effect, as is seen by comparing the map in column 4 to the map in column 1 . It is interesting that we saw no case in which the firing pattern in initial darkness was a rotated version of the field in initial light.

The 8 cells whose firing patterns were unchanged between initial light and initial darkness have the same pattern in all 5 segments of the combined L-D-L and D-L sequences. These cells fired in the same way, independent of light level and the time order of light and dark; an example is shown in Figure $5 B$. In contrast, the firing patterns of 3 of 22 cells were altered by darkness in both the L-D-L and D-L sequences, so that their activity was apparently dependent on visual cues.

When more than one cell was recorded from an individual rat, we looked to see if all cells persisted or did not persist in initial darkness, or if there was a mixture of the 2 kinds of responses. Seven of the 10 rats yielded 2 or more cells. Both cells that persisted and cells that did not persist in initial darkness were observed in individual rats. Furthermore, persistent cells were encountered both before and after cells that did not persist. These observations suggest that persistence during initial darkness is a property of individual cells and not a characteristic of individual animals.

In summary, the 22 cells tested in both the L-D-L and D-L sequences can be divided into 3 groups, based on the effects of darkness. The largest group, called "persistent/nonpersistent," was unaffected by darkness when it was immediately preceded 

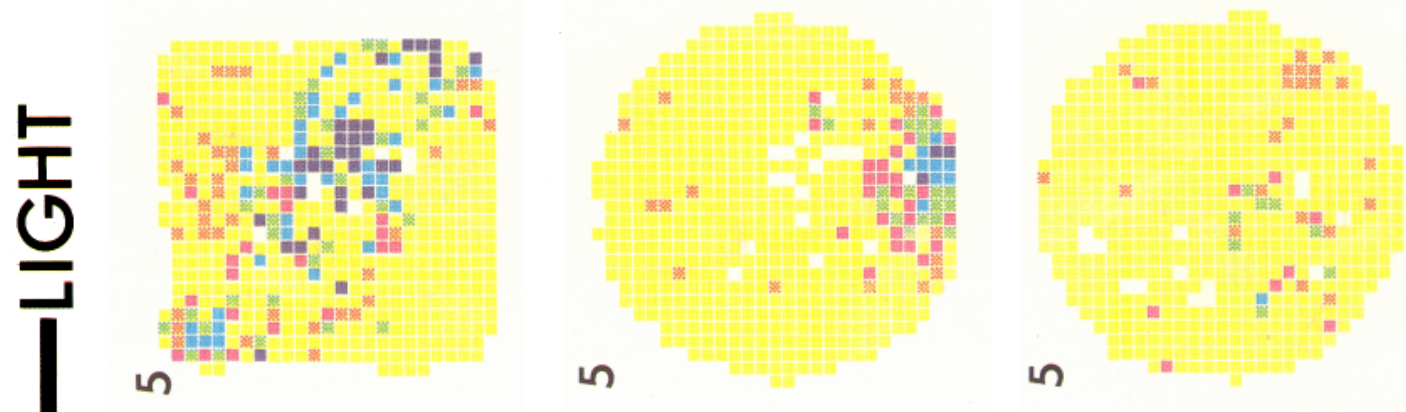

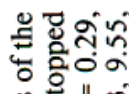

कै का 11

ฮี่ำ

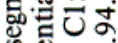

䗆

⿷匚्

웡

范

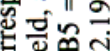

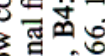
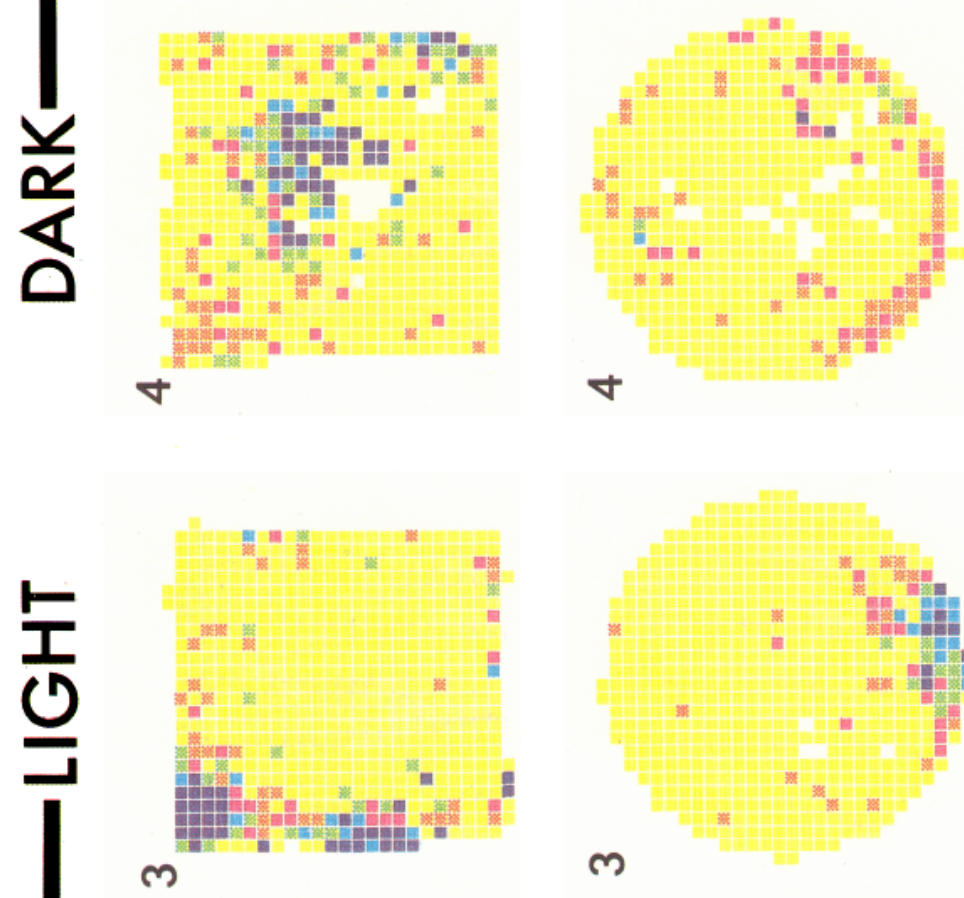

$m$

$m$

स엇

E

要三

है

的苾㝴

E

这茄

름

寸

政

ชั

월.

명

o x ॥

吅

青宅进

을

与ํㅇ잉

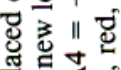

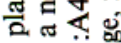

综示

항

च

g.

든

3 过要

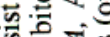

政

중

일

을

하영

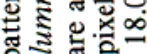

on

$N$

$N$

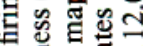

政

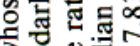

函势

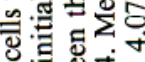

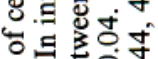

论

을

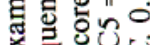

就

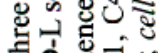

它解

ช

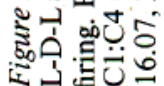




\section{LIGHT}

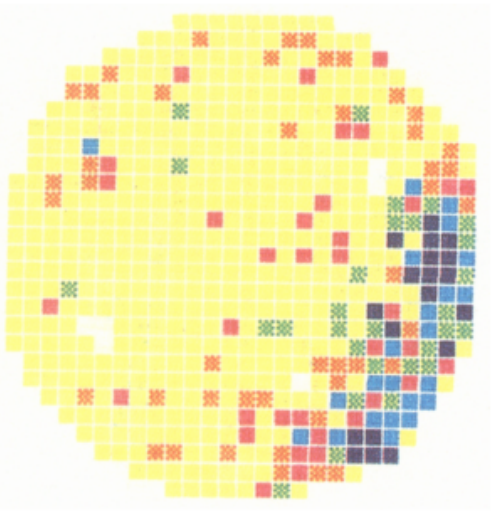

Figure 4. Firing rate map for a lighted, $8 \mathrm{~min}$ recording session that was run subsequent to the D-L sequences for the cell shown in Figure $3 C$. This cell, which showed a firing field at 4 o'clock in the cylinder in the L-D-L sequence, stopped firing when the rat was put into the darkened chamber (Fig. 3). The map above shows that the firing-field returned in a subsequent lighted session. Median rates of pixels are as follows (order: yellow, orange, red, green, blue, purple, in $\mathrm{Hz}$.): $0.0,1.5$, $3.3,6.2,10.0,13.8$.

by a lighted segment but showed different firing patterns in initial darkness ( 11 cells). The second group, "always persistent," was unaffected by either dark condition ( 8 cells); and the third group, "never persistent," showed altered firing patterns in both dark conditions ( 3 cells).

\section{Firing during the lighted half of the D-L sequence}

Of the 14 cells whose firing pattern changed in initial darkness, 12 were tested to see if the pattern in initial darkness would be maintained when the lights were turned on. The firing pattern of 4 of the 12 cells reverted to the pattern seen in initial light in the L-D-L sequence; an example is shown in Figure 3, row B (map B5). In contrast, the other 8 cells continued to fire in the light in the same altered way as when the rat was initially in the dark. Two examples of this type are shown in Figure 3, rows $A$ and $C$ (maps A5 and C5). Thus, two-thirds of the cells that showed altered firing patterns in the dark persisted in the altered pattern when the lights were turned on and did not revert to the pattern seen in the initial light segment.

\section{Firing subsequent to the $D$ - $L$ sequence}

Five of the 8 cells whose firing pattern was altered in both segments of the D-L sequence were tested in a subsequent lighted session to see if spatial firing would reset to the pattern originally observed in the light. In all 5 cases, placing the rat in the lighted chamber for a new session caused the firing to reset; the pattern in the third session strongly resembled the pattern in the first lighted segment (mean persistence $=0.531$ ) rather than the lighted half of the D-L sequence (mean persistence $=0.115$ ). Figure 4 shows the firing rate map of the third lighted session for the cell of Figure 3, row C. This cell had a field in the cylinder at 4 o'clock in the L-D-L sequence and no field in the D-L sequence. When the rat was subsequently put into the lighted cylinder, a field was observed in the same position as the original L-D-L field.

Two hypotheses are available to explain the reversion to the
L-D-L firing pattern of cells recorded in the third lighted session. On the one hand, it could be that the time order of light and dark is crucial. Alternatively, it is possible that the firing of this class of cells is constant when the lights are turned on after initial darkness because of odor or other cues from floor markings made by the rat in the dark. In this view, the spatial pattern reverts in the third lighted session because the floor paper is replaced. To test this hypothesis, the floor paper was not replaced for 2 of the 5 cells tested in the third lighted session. In both cases, firing reset to the pattern seen in initial light, despite the presence of floor markings from the previous D-L session. This suggests that floor markings were not important determinants of the persistence of spatial firing patterns when the lights were turned on after initial darkness.

\section{Responses of pairs of simultaneously recorded cells}

On 4 occasions, it was possible to record from pairs of place cells simultaneously. The pairs were examined to see if the member cells were affected in the same way by initial darkness. In 3 out of 4 cases, both cells of the pair persisted in the L-D-L sequence and changed firing patterns in the D-L sequence. In the fourth case, the cells in the pair were affected differently from each other, as shown in Figure 5. Unit 1 (row A) persisted throughout the protocol, but unit 2 (row B), which showed no field during the L-D-L sequence, developed a field in initial darkness. This finding suggests that different responses to an environmental change, such as turning off the lights, can be present in different cells in the hippocampus simultaneously.

\section{Discussion}

In this study, the effects of darkening the rat's environment on the firing of hippocampal place cells were investigated with quantitative methods. We found that spatial firing in the dark is persistent for most cells if the lights are turned off when the rat is already in the recording chamber. Numerically, firing patterns in the dark differed from those in the light only to the extent expected for repeated observations in the light. This primary finding confirms the qualitative work on place cells reported by O'Keefe (1976) and is in line with the preliminary quantitative study made by Jones-Leonard et al. (1985) on the effects of darkness on the firing of cells in the dentate gyrus.

\section{Persistence of spatial firing in the dark}

By itself, persistence in the dark after initial light can be explained by the finding that place cells can use auditory, olfactory, and tactile information, as well as visual information to support spatial firing (O'Keefe and Conway, 1978). In this view, a given place cell is triggered by a subset of the particular polymodal cue constellation (including, perhaps, proprioceptive cues) that is present in the region of the cell's firing field. If all visual cues are removed, this model predicts that cells that are sensitive to nonvisual components of the constellation will continue to fire in the same region. In contrast, cells that are sensitive to only visual stimuli are expected to cease firing. The fact that 24 of 28 cells persisted in the dark therefore suggests that most place cells are controlled by nonvisual as well as visual stimuli. In turn, the fact that 4 cells failed to persist suggests that some cells depend critically on visual input for reliable spatial firing. It is also useful to note that an additional mechanism is necessary to account for the observation that the firing rate in general does not decrease in the dark, despite the removal of activating stimuli. It could be postulated, for example, that the negative feed- 

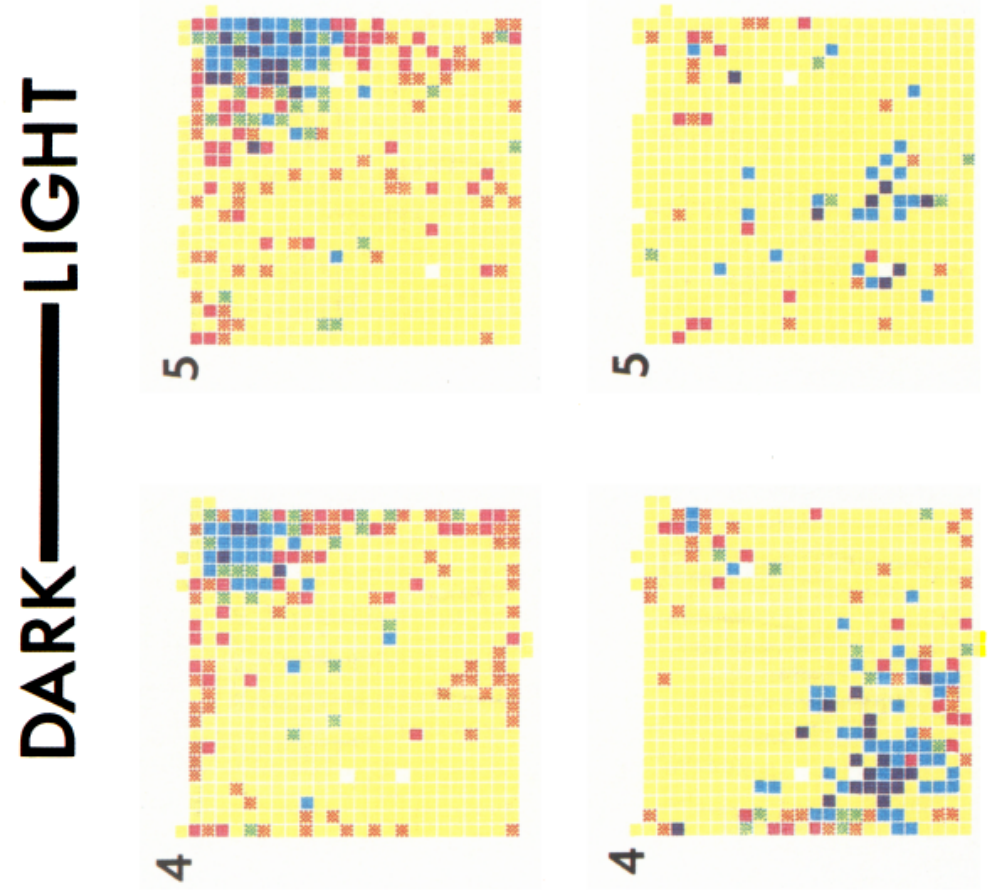

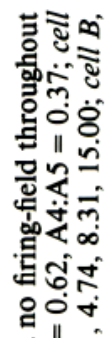
छाँ 总这家 जल so. क्I क्ष

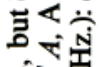
. 范言芦 的흐음 跣
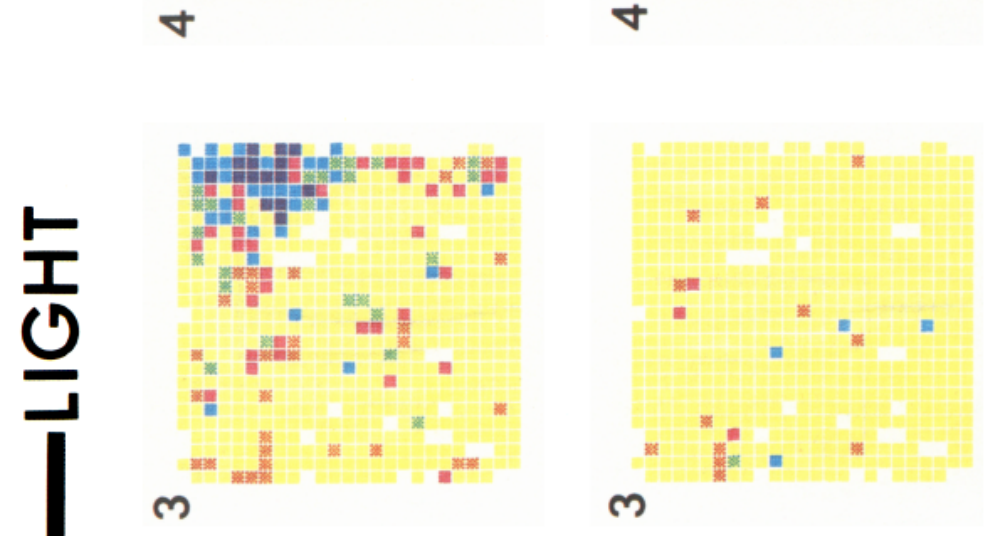
back provided by inhibitory interneurons maintains a nearly constant overall firing rate for complex-spike cells.

Two schemes can be described to explain how it is possible for spatial firing to be stationary in the dark after an initial lighted period. The first variant postulates that the essential cues are static features of the environment. In this model, both visual and nonvisual environmental cues contribute to place cell firing in the light, and the nonvisual subset supports firing in the dark. The alternative is that in the dark the rat keeps track of its position with vestibular and proprioceptive information. When the lights are turned off, the rat updates its position in an independent representation of the environment by path integration or dead reckoning (Gallistel, 1989). It is possible that the stationarity of spatial firing in the dark depends on both environmental and kinesthetic information. We cannot rule out the possibility that place cell firing in the dark relies only on dead reckoning. Nevertheless, we think it is unlikely that path integration can be sufficiently accurate to maintain constant field location over intervals as long as $8 \mathrm{~min}$, since the stored integral is subject to cumulative error without external feedback.

\section{The role of memory in establishing spatial firing patterns}

Although the "sensory summation" model explains persistence in the dark following light, the effects of initial darkness show that sensory cues cannot be the only determinant of spatial firing patterns in the dark. The summation model predicts that the firing of the cell should vary only with position, independent of the history that leads up to the current cue state, or in other words, that firing in any light or dark segment should be independent of preceding conditions. It was found, however, that firing in the dark varied with the rat's previous experience. If a light segment preceded the dark segment, firing patterns were generally similar in both. In contrast, if the rat was introduced directly into a darkened chamber, firing usually did not resemble that in earlier light or dark segments. Likewise, firing in the light was sensitive to recent experience; for many cells, firing in the lighted segment of the D-L scquence rescmbled that in the immediately preceding dark segment but not other lighted segments.

The dependence of spatial firing patterns on conditions that precede recording in the dark or light implies that place-cell activity can reflect a memory of an earlier condition in the environment. We therefore conclude, in agreement with O'Keefe and Speakman (1987), that hippocampal place cells have access to recent memory. It is important to note that our results do not speak to the question of whether the memory has any content. In other words, it is possible that appropriate testing would reveal that the animal can alter its behavior according to the earlier lighting condition. Alternatively, it is possible that the earlier experience only sets the state of the hippocampus, which is then stable for the duration of the session but does not have access to information about specific preceding events.

A number of other studies have demonstrated mnemonic properties of hippocampal cells recorded in freely moving rats. In conditioning paradigms, the response of hippocampal cells was shown to be modulated by the valence of preceding trials (Eichenbaum et al., 1987; Foster et al., 1987). Thus, it appears that the recent experience of the rat with respect to many facets of the environment can modulate the current firing of hippocampal complex-spike cells.

\section{Conclusions about the nature of the hippocampal representation of the environment}

If the hippocampal representation of the surroundings is taken to be maplike (O'Keefe and Nadel, 1978), the pattern of changes in spatial firing produced by initial darkness can be described with the notion of "remapping" (Muller and Kubie, 1987). When place cells with firing fields in the cylinder were also recorded in a rectangular apparatus, it was found that all cells either ceased firing or exhibited unrelated fields; the spatial firing patterns did not transform so as to mimic the topological change in the apparatus shape (Muller and Kubie, 1987). The fact that the set of active cells changes from cylinder to rectangle and that cells that are active in both apparatuses have unrelated fields was described as a "complete remapping."

Similar effects were seen in this study for 11 of 22 cells recorded in initial darkness; 6 cells developed new fields that bore no resemblance to the fields seen in the light, while 5 cells stopped firing. On the other hand, 8 cells fired in the same way during initial darkness as they did during initial light; the remaining 3 units had smeared versions of their initial light fields. It is convenient to refer to these results as a "partial remapping" of the environment. A partial remapping also was seen when the cylinder was scaled up by a factor of 2 , wherc about half the cells showed new firing fields or stopped firing, and the firing fields of the other half scaled along with the apparatus scaling (Muller and Kubie, 1987).

We suggest that the extent of remapping reflects an estimate by the rat's spatial system of the magnitude of the difference between 2 environments. Thus, when the rat is moved from the cylinder to a scaled or darkened version of the cylinder, some place cells register the difference between the 2 environments and show completely different firing fields. In contrast, other cells register the similarity of the 2 environments by showing persistent or scaled firing fields. The coexistence of a persistent and a nonpersistent cell in initial light suggests that the hippocampal representation can simultaneously reflect similarities and differences between environments.

Perhaps the most surprising finding reported here is that the altered firing of cells recorded in dark-first sessions did not revert to the light-first pattern when the lights were turned on. This suggests that the environmental representation signaled by the place cell population is established at the beginning of a session and is resistant to cue deletions or additions made during the session. This within-session stability bears a strong resemblance to trial-specific or working memory (Honig, 1978).

In summary, the properties of place-cell firing in the dark provide additional evidence that the firing of hippocampal place cells can be strongly dissociated from the currently available configuration of salient cues (O'Keefe and Conway, 1978; Bostock et al., 1986; Muller and Kubie, 1987; O'Keefe and Speakman 1987; Sharp et al., 1988). We have also shown that placecell activity in the dark reflects the recent experience of the rat in the recording chamber; this is a further demonstration that hippocampal cells have access to recent memory.

\section{References}

Berger TW, Rinaldi PC, Wcisz DJ, Thompson RF (1983) Single-unit analysis of different hippocampal cell types during classical conditioning of the nictitating membrane response. J Neurophysiol 50: 1197-1219. 
Birch D, Jacobs GH (1975) Behavioral measurement of rat spectral sensitivity. Vision Res 15:687-691.

Bostock E, Muller RU, Kubie JL (1986) Firing fields of hippocampal neurons: a stimulus manipulation that alters place cell mapping of the environment. Soc Neurosci Abstr 12:522.

Eichenbaum H, Kuperstein M, Fagan A, Nagode J (1987) Cue-sampling and goal approach correlates of hippocampal unit activity in rats performing an odor discrimination task. J Neurosci 7:716-732.

Foster TC, Christian EP, Hampson RE, Campbell KA, Deadwyler SA (1987) Sequential dependencies regulate sensory evoked responses of single units in the rat hippocampus. Brain Res 408:86-96.

Gallistel CH (1989) The organization of learning. Cambridge, MA: MIT Press.

Hill AJ, Best PJ (1981) Effects of deafness and blindness on the spatial correlates of hippocampal unit activity in the rat. Exp Neurol 74: 204-217.

Honig WK (1978) Studies of working memory in the pigeon. In: Cognitive processes in animal behavior (Hulse $\mathrm{SH}$, Fowler $\mathrm{H}$, Honig WK, eds). Hillsdale, NJ: Erlbaum.

Jarrard LE (1983) Selective hippocampal lesions and behavior; effects of kainic acid lesions on performance of place and cue tasks. Behav Neurosci 97:873-889.

Jones-Leonard B, McNaughton BL, Barnes CA (1985) Long-term studies of place field interrelationships in dentate gyrus neurons. Soc Neurosci Abstr 11:1108.

Kolb B, Pittman K, Sutherland RJ, Wishaw IQ (1982) Dissociation of the contributions of the prefrontal cortex and dorsomedial thalamic nucleus to spatially guided behavior in the rat. Behav Brain Res 6: 365-378.

Kubie JL (1984) A drivable bundle of microwires for collecting single unit data from freely moving rats. Physiol Behav 32:115-118.

Morris RGM, Garrud P, Rawlins JNP, O'Keefe J (1982) Place navigation impaired in rats with hippocampal lesions. Nature 297:681683.

Muller RU, Kubie JL (1987) The effects of changes in the environment on the spatial firing of hippocampal complex-spike cells. J Neurosci 7:1951-1968.

Muller RU, Kubie JL, Ranck JB Jr (1987) Spatial firing patterns of hippocampal complex-spike cells in a fixed environment. J Neurosci $7: 1935-1950$.

Muntz WRA (1967) A behavioral study on photopic and scotopic vision in the hooded rat. Vision Res 7:371-376.
O'Keefe J (1976) Place units in the hippocampus of the freely moving rat. Exp Neurol 51:78-109.

O'Keefe J, Conway DH (1978) Hippocampal place cells in the freely moving rat: why they fire where they fire. Exp Brain Res 31:573-590.

O'Keefe J, Dostrovsky J (1971) The hippocampus as spatial map. Preliminary evidence from unit activity in the freely moving rat. Brain Res 34:171-175.

O'Keefe J, Nadel L (1978) The hippocampus as a cognitive map. London: Clarendon.

O'Keefe J, Speakman A (1987) Single unit activity in the rat hippocampus during a spatial memory task. Exp Brain Res 68:1-27.

Olton DS, Walker JW, Gage FH (1978) Hippocampal connections and spatial discrimination. Brain Res 139:295-308.

Olton DS, Becker JT, Handlemann GE (1979) Hippocampus, space and memory. Brain Behav Sci 2:313-365.

Paxinos G, Watson C (1982) The rat brain in stereotaxic coordinates. Sydney: Academic.

Quirk GJ, Muller RU (1989) The firing of entorhinal place cells is more sensory bound than that of hippocampal place cells. Neurosci Abstr. 15:404.

Quirk GJ, Muller RU, Kubie JL, Ranck JB Jr. (1987) Hippocampal and entorhinal place cells: what happened when the lights went out. Soc Neurosci Abstr 13:1331.

Ranck JB Jr (1973) Studies on single neurons in dorsal hippocampal formation and septum in unrestrained rats. Exp Neurol 41:461-555.

Sharp P, Kubie JL, Muller RU (1988) Hippocampal place cells can fire differently in two visually identical locations. Soc Neurosci Abstr $14: 126$.

Sutherland RJ, Wishaw IQ, Kolb B (1983) A behavioral analysis of spatial localization following electrolytic, kainate- or colchicine-induced damage. Behav Brain Res 7:133-153.

Taube JS, Muller RU, Ranck JB Jr. (1990a) Head-dircction cells recorded from the postsubiculum in freely moving rats. I. Description and quantitative analysis. J Neurosci 10:420-435.

Taube JS, Muller RU, Ranck JB Jr. (1990b) Head-direction cells recorded from the postsubiculum in freely moving rats. II. Effects of environmental manipulations. J Neurosci 10:436-447.

Wiener SI, Paul CA, Eichenbaum H (1989) Spatial and behavioral correlates of hippocampal neuronal activity. J Neurosci 9:2737-2763. 